\title{
Changing Paradigms of Media Landscape in the Digital Age
}

\section{Vineet Kaul*}

Department of Communication and Media, DA-IICT University, Near Indroda, Gandhinagar, Gujarat, India

\begin{abstract}
Digital technologies have fundamentally altered the nature and function of media in our society, reinventing ageold practices of public communication and at times circumventing traditional media and challenging its privileged role as gatekeepers of news and entertainment. We know the world is changing. And we believe research needs to change too. This article discusses how new media landscape has irrevocably altered how people interact with each other, how communities are formed, how opinions are shared. This landscape is technology-led and technologyenabled, and has occasioned key shifts in the way consumers think about the world around them and about brands. The article aims to explore and understand the impact of digital technology on our traditional media and find out how these technologies are enabling media professionals around the world in their respective areas. The focus is also on the usage of digital technology in mass media and its impacts on our society and the future of new technology.
\end{abstract}

Keywords: Media landscape; Digital age; Traditional media; Digital technology; Communication

\section{Introduction}

Change in the media landscape is constant. We live amid the greatest change in the history of media. The nature and magnitude of this epochal change are so enormous that most media executives and media scholars fail or refuse to recognize it and that the others who do claim to see it instead mistake its traits or characteristics as the change itself. Technology and its current applications have evolved at lightning pace transforming the media landscape. Everyone involved in the production of creative content - photographers, journalists, writers, and musicians, as well as those who deal in those products knows that nothing is as it was. They support transformational ideas that promote quality journalism, advance media innovation, engage communities and foster the arts .It is believed that democracy thrives when people and communities are informed and engaged. As more media become increasingly available in digital formats, and traditional models of media packaging and distribution start to unravel, "the customer is king" is fast becoming the industry's new catchphrase. However, the bulk of culpability recently shifted to another group: the media executives and media scholars who claim to see the change yet mistake a trait or characteristic as the change itself. They, not those who refuse or fail to recognize the change, are now most responsible for their industries' failure to adapt to the change. The trick for media companies is how to embrace multiple content in a profitable way and the scope will exist for far greater personalisation of all forms of content, and end users will be empowered and have greater influence, controlling how, where and at what price they consume content. New media has changed the way people perceive, reflect, react and interact with each other.

As journalism leaders and luminaries have been writing for quite some time now, the epochal change in the history of media is that, within the span of a single human generation, people's access to information has shifted from relative scarcity to surfeit. Billions of people whose access a generation ago to daily changing information was at most one or two or three locally-distributed printed newspapers, one, two, three, four television channels, and one or two dozen radio stations, can now access virtually all of the world's news and information instantly at home, office, or wherever they go. The economic, historical, and societal ramifications of this epochal change in media will be far more profound than Gutenberg's invention of moveable type, Tesla's and
Marconi's invention of broadcasting, or any other past development in media.

Digital technologies have fundamentally altered the nature and function of media in our society, reinventing age-old practices of public communication and at times circumventing traditional media and challenging its privileged role as gatekeepers of news and entertainment. Some critics believe these technologies keep the public involved in an informed discourse on matters of public importance, but it isn't clear this is happening on a large scale. Propaganda disguised as news is flourishing, and though interaction with the digital domain teaches children valuable skills, it can also expose them to grave risks. Attempting to convey a clear picture of the modern media landscape is like trying to draw a hurricane from within the storm. In our review of the industry's history, we note that leaders of each medium believed that the latest new technology would doom them, yet many survived and adapted. And yet this sense that the future is unknowable cannot be used as an excuse for failing to attempt to understand what is happening around us now-especially when history has shown that in transformative moments like this, decisions made by policymakers and industry leaders reverberate for decades. The digital age has arrived with a set of big communication challenges for traditional mainstream media: new relations with audiences (Interactivity), new languages (Multimedia) and a new grammar (Hypertext). But this media revolution not only changes the communication landscape for the usual players, most importantly, it opens the mass communication system to a wide range of new players.

As far as enterprises, institutions, administrations, organizations, groups, families and individuals start their own web presence, they become "media" on their own, they also become "sources" for

*Corresponding author: Vineet Kaul, Department of Communication and Media, DA-IICT University, Near Indroda, Gandhinagar, Gujarat, India, Tel: 091 9825934642; Fax: 26831400; E-mail: vineetkaul2404@gmail.com

Received November 28, 2011; Accepted February 03, 2012; Published February 05, 2012

Citation: Kaul V (2012) Changing Paradigms of Media Landscape in the Digital Age. J Mass Communicat Journalism 2:110. doi:10.4172/2165-7912.1000110

Copyright: @ 2012 Kaul V. This is an open-access article distributed under the terms of the Creative Commons Attribution License, which permits unrestricted use, distribution, and reproduction in any medium, provided the original author and source are credited. 
traditional media, and, in many cases, they produce strong "media criticism": opinion about how issues are covered and delivering of alternative coverage. The blogging phenomenon represents the ultimate challenge for the old communication system because it integrates both: the new features of the digital world and a wide democratization in the access to media with a universal scope. A new 'model' is potentially on the horizon that may include elements of 'shared' resources and apportioned rewards both in terms of recognition and monetary value. There will of course be resistance on both sides - seismic changes in the production and economy are always disruptive but the media landscape is already changing shape and the power of mass collaboration combined with the Internet will ensure that it never look the same again

Through the innovative use of new digital technologies, the Media industry has a very different competitive landscape than found earlier developed for analog media production and distribution. Technology has now lowered the barriers to entry, broadened distribution to a global audience, and democratized media production. It is also enabling a reevaluation by media, telecommunications, computer, and IT service companies of their positions in a constantly changing industry .The media industry has been under turmoil since the rise of digital media platforms which have impacted upon many aspects of the media industry of old. These changes, combined with an economic downturn, have led to much unrest in the media sector. Major competing sectors include TV and radio broadcasting, newspaper publishers, film and video industries. With the advent of the digital age, Media has transformed the way news and entertainment content is disseminated around the world. In this age of Information Technology, sources of news gathering and reporting have undergone a dramatic paradigm shift. An increase in the demand of digital media and information communication technology in a borderless world has encouraged many countries to a new era of knowledge creation and fast-moving competitive advantages especially in the media sector. This phenomenon has blurred boundaries between the broadcasting and computing industries in terms of their roles, functions, and economic scale. In most ways today's media landscape is more vibrant than ever, offering faster and cheaper distribution networks, fewer barriers to entry, and more ways to consume information. Choice abounds. Local TV stations, newspapers and a flood of innovative web start-ups are now using a dazzling array of digital tools to improve the way they gather and disseminate the news-not just nationally or internationally but block-by-block. In an age in which news can travel the globe in a nanosecond, it is more important than ever that practicing journalists be able to provide their audiences with more than "just the facts" or "just the video."

The changing media landscape, locally and globally, bring with it certain challenges and opportunities. A new media landscape has irrevocably altered how people interact with each other, how communities are formed, how opinions are shared. This landscape is technology-led and technology-enabled, and has occasioned key shifts in the way consumers think about the world around them. There is a fear within the marketing world that the TV and broadcast model is becoming obsolete and that connected empowered youth are deserting traditional media. Brands are looking for new communications solutions and are increasingly asking market research companies for strategic thinking around this. Recent developments such as peer-topeer systems have dramatically changed how media can be distributed. This changes the dynamic of our media culture from the top-down hierarchical model we have today, to the user centered model that is emerging. We have seen many such changes already - user generated content of blogs and sites such as MySpace, the opening of distribution via sites like YouTube. Peer-to-peer is already estimated to be around $60 \%$ of Internet traffic. How will this shift from mass media to a form of network media impact on the content of media? How will it impact the wider media culture and how will it be used and adapted in turn? How has the News used corporate messages to respond to the changing media landscape?

People are also crafting their own forms of media and creating their own content without waiting for traditional institutions (record labels, publishers, film studios) to sanction it. Trendwatching.com have dubbed them Generation C (for Content), a new breed of empowered, talented young people who can make films, artwork, records and books from their bedrooms and are not waiting for permission to release it to their public in the form of blogs, online photo albums, personal websites. A tidal wave of creativity has flooded cyber space, and surfing it is no longer a passive absorbing of information. Tools like iMovie, Final Cut Pro, Garage Band, Cubase and PhotoShop have democratised creativity - now anyone can make films, art and music from their bedrooms. New social networks and content aggregators have sprung up to host this generation's creative output (sort of virtual cinemas, art galleries and libraries) like Myspace and Youtube. The popularity of these creative reservoirs is a testament to a generation that wants to put their own self-expression out there and receive reassurance and approbation from their peers in the form of comments and links. And nothing illuminates this new age of creativity, empowerment and interactivity more than the explosion of the blogosphere. Blogs, or online journals written by individuals and published on the web, have been the marketing buzzword of the last few years and their number, influence and relevance increases day by day. When information has become a digital commodity: easily accessible -at almost no cost, anytime, everywhere. Do we still need journalists? Do we need reporters when the web lets us travel to every corner of the world? Do we need investigative journalists when they would never get the documents that WikiLeaks got? Do we need international correspondents when demonstrators in Iran can send pictures of their prohibited protests via mobile phones to the web? Do we need editorials when the web offers us millions of opinions?

Technology has opened doors that have created a new mindset amongst young people. The rise of blogging, sharing music, downloading information, taking part in chat rooms, bulletin boards and online communities has occasioned a new set of values. Consumers have moved from an Age of Competition (importance of 'Me') to an Age of Cooperation (importance of ' $\mathrm{We}$ '). There has been a realisation that to get ahead, life should be about participation, involvement and openness rather than aggressive individualism. Far from the apathetic breed of adolescents the media presents, technology has helped create a new mindset that is more about taking part and pro-activity: a 'lean forward' attitude. Not only this, but they are a generation of 'commentators' who are constantly connected, communicating frequently and generating debate. The ease and multiplicity of communication media means that people have and share more opinions than ever before.

For better or worse, the media landscape isn't what it used to be. Yes indeed, times they are a changing'! Over the last fifteen or so years huge advances in the nature of digital technology have spawned a wide array of new media platforms, channels and delivery mechanisms through which you receive (and sometimes deliver) a staggering amount of content. This changing landscape provides you, both as a consumer 
and producer of media, with many exciting new options to consider when choosing how and from where you get your information. This newfound richness of options comes at a price, though. Exercising the many options you are now confronted with can sometimes be a bit more complicated than operating your television's remote control unit. This is true when you are acting solely as a media consumer but is of equal, if not greater, concern when you find yourself at the other end of the consumption spectrum, as a producer. Since the purpose here is ultimately to help future media professionals-like yourself- find their way through this potential morass, we'll focus most of our energy on your role as a producer.

If you're even somewhat up to speed with what today's media landscape looks like, you know that getting your daily measure of media, regardless of type or how it's delivered or even how it's produced, isn't as simple as it used to be. Sure, you can still turn on the tube, change a channel or two, and, just like you used to do, slip into autopilot mode while watching the evening newscast. However, if you want to engage with content of the new media type, then you've got to be willing to become more actively involved. This willingness on your part will reap you two great rewards: "more" and "now." You arrive at the "more" through the simple fact that new media are ubiquitous. Content is everywhere and is provided to you through myriad distribution channels. You have at your disposal a wide selection of media content. The World Wide Web alone presents you with a breadth of information that is far greater than even the most robust cable television services can provide. Your willingness to engage with new media as a means of obtaining information undoubtedly exposes you to a wider swath of more and better content.

To get to the "now," you need only consider another simple truism of virtually all new media: It's always available. The delivery of new media content isn't relegated to a specific time of day or day of the week, as is the case with most traditional broadcast media such as television or radio programming. New media aren't delivered to your home or office each day at a certain time-thinks newspapers- or each week or month-think magazines. New media are instead instantly available to you at all times of the day or night and they're constantly updated. When a news story breaks, articles shows up on numerous Web sites only minutes after they've been written. As new developments to the story arise, the available content is updated on the fly. The same phenomenon definitely doesn't happen with traditional print media and rarely does with broadcast media unless, of course, the particular news event is of such stupendous concern that there's a need-and willingness-to break into regular programming.

Normally, with older forms of media, you're forced to wait for the next day's newspaper delivery or the evening news broadcast or your favorite radio show to access the same information that you can get twenty-four hours a day by visiting one of many new media resources. Yes, media content-and the ways in which you use it and create it-is definitely changing. A large percentage of the content we consume has actually already changed quite a bit; the rate of that change is accelerating faster and faster. Technological innovations keep the new media landscape continually in flux. It really doesn't take all that long for nascent technologies to lose the sheen of their newness. Fresh platforms, software tools, and hardware devices arrive on the scene with alarming frequency making the job of defining exactly what the media landscape looks like today a difficult task, a moving target at best. Before attempting to do so, it's important that you first take a closer look at what types of media currently at your disposal are more or less the same as they've been historically, what's already changed, and what new forms will likely be available in the very near future.

\section{The Digital Media Value Chain}

We are entering into a golden age of content and media. Today, media companies are investing huge sums of money in non-traditional media delivery options, start-ups are innovating and redefining how the content industry works, and consumers are demanding and expecting access to virtually any content on any device at any time. This includes media and entertainment content, but also corporate, social, marketing and personal media. The tectonic shifts happening in the media and content world are going to irreversibly reshape how companies and consumers create, display, view and consume content.

Innovation within the content space has been largely driven by and accomplished through the continued digitization of content, including traditional media and business media-corporate and internal communications, marketing and sales collateral, HR, accounting, document and productivity solutions-across verticals, regions, divisions, and throughout the supplier and customer value chain. At the same time, media companies are realizing that by digitizing and managing their assets, they can gain greater control, allow for simpler creation and collaboration, enable diverse distribution through multiple media gateways, and can positively impact monetization efforts. This ever-increasing creation, conversion, and retention of digital content has created entirely new industries, business dynamics, competitive paradigms, and demands on technology. Data from Worldmapper.org, Computeruser.com and Internetworldstats.com show that in 1990, a mere 0.25 percent of the world's population was a cell phone subscriber, and a paltry 0.05 percent of the population used the Internet. In 2010, these numbers have jumped to 4 billion people-or a whopping 67 percent of the world's population-subscribing to mobile services and close to 2 billion or 26.6 percent of the world's population using the Internet. This seismic shift over the past two decades has been driven by an explosion in digital content fueled by high bandwidth penetration, changing the consumer and enterprise landscape forever.

As a result, burgeoning digital media and content libraries have strained the resources of traditional storage, retrieval, and management systems; a diversity of content-capable devices has created new challenges for companies to enable multi-screen viewing; and the intensity of ever-present competition between media companies has driven them to create compelling interactive media platforms, alternative advertising and monetization schemes, and engaging user experiences designed to fit the demands of an ever-more voracious yet selective consumer market. Most media companies today have come to realize that to gain the best advantage of their digital media assets and meet the needs of their customers, they must deploy scalable, integrated and synergistic content, business, and customer experience management technologies. The value proposition of deploying these solutions and their related ROI has been proven repeatedly within the digital media industry, as enterprise spend and deployment around these content management systems has more than quadrupled in the past five years; as needs escalate and technologies advance, media companies must invest in these solutions to remain agile, competitive, and viable. "Most media companies today have come to realize that to gain the best advantage of their digital media assets and meet the needs of their customers, they must deploy scalable, integrated and synergistic content, business, and customer management technologies." 


\section{Defining Old Media and New Media}

The question whether old media are driven out of existence by new media has been a long concern in academic and industrial research but has received no definitive answer. We can't get all worked up about the changing media landscape or about all the new tools that pop-up every day. We can't throw out everything we know about media every time a new tool comes around because these tools are at our service to help us improve our storytelling not to intimidate us. New Media, Old Media is a comprehensive anthology in digital culture. Leading international media scholars and cultural theorists interrogate new media like the Internet, digital video, and MP3s against the backdrop of earlier media such as television, film, photography, and print. We've reached a point in the developmental trajectory of the media industry that we can refer to media as being either "new media" or "old media" without getting into too much trouble. It's been a lot of fun, this longrunning sniper's war between Old Media and New Media. We've all enjoyed some hilarious slap-downs, all marveled at the sheer idiocy of the morons on the other side. ( $\mathrm{Oh}$, and let's not forget their over-thetop mean-spiritedness.) But all fun things must end. Old media and old law have been learning a salutatory lesson about the power of new media and it is time to put the Old vs. New Media war to rest. This framework, old vs. new, hasn't been wholly wrong. For a long time it has mostly reflected facts on the ground. Old media was in the moneymaking driver's seat and spent long hours scoffing and chortling at the new-media prophets. New media would not be outdone on the scoffing front, convinced that the digital revolution would change everything, if only old media would get out of the way. The battle lines were drawn and fixed. And there they would stay and say:

- New media is having a conversation; old media is delivering a lecture

- Old media takes itself very seriously; new media has a sense of fun

- New media welcomes criticism and attempts to learn from it, getting involved in the discussion; old media sees it as an attack, goes on the defensive, and even tries to exact revenge

- Old media is establishment; new media is counter-culture

- Old media refuses to acknowledge peer publications; new media shares the link love

- Old media is an exclusive club; new media is open to all

- Old media thinks twitter is a frivolous waste of time; new media doesn't know how it managed before twitter came along

- Old media constantly tells everyone how good and successful it is; new media leaves that job to others

- Old media plays it safe and seldom gets it wrong; new media frequently gets it wrong, but apologises and carries on, regarding this to be the price paid for working closer to the edge

- Old media is so competitive about its search engine ranking that it uses underhand tactics such as 'rel=no_follow' tags on outward links (google it if you don't know what this is), to avoid bleeding page rank; new media recognizes that sharing and collaboration are the way forward
- Old media has 10000 twitter followers but follows just 12; new media has 10000 twitter followers but follows 2500

- Old media are what you're accustomed to: television, radio, newspapers, magazines, etc. New media are most often associated with content that's accessible "online," which simply means that the information is available via a virtual network, the Internet being the most obvious.

Navigating these waters will require a new blend of business, technical and creative skills. Success will necessitate comfort with technology, openness to change, aggressiveness with resource commitments and willingness to take some calculated risks. Given the uncertain environment at this stage, the chorus of concerned corporate citizens is understandable. Yet from this chaos will emerge a new Media construct. As the dust settles, entertainment - now in digital form - will experience a boon on a scale never witnessed before in Media history.

New media technology is rapidly evolving the media industry and the practices of mass communications. New media technology is the application of digital (computer) technology to mass communications. In a few short years, two main factors associated with the technology have changed the media landscape. The Internet emerged as a communication medium. Even though the Internet is still in its infancy, its impact on society, commerce, and the government is already phenomenal. In addition, the interactivity and immediacy inherent in digital technology have changed the models of media production and business for all media. Traditional and new media incorporate characteristics of and influence each other; that is, media converge. As such, it is becoming increasingly important to understand new media technology and the changes it brings to the media industry. In a few short years, digital technology has become an integral part of media production and distribution. It has also established itself as a communication medium rivaling print and broadcast. As such, digital technology is the new media technology of today and the future. Professionals in journalism, public relations, advertising, broadcast, and mass communications are being confronted with a new and still evolving media landscape.

Historically, media technologies have taken many years to go through stages of development, introduction, adoption, and wide acceptance. The current media technology has exploded in less than a decade and is continuing through development with no end in sight rather than growing to maturity. Theorists and practitioners alike are not yet able to predict the direction of the technology or its effects. It is still changing too rapidly. These effects occur both on the presentation of the media product itself, as stated above, and on the production of media. Production involves a series of processes: acquiring, processing, distributing, and storing information. Digital technology is currently used in each of these processes regardless of the media of the finished product.

New media technology is the application of digital (computer) technology to mass media, specifically media production, distribution, storage, and use. Digital technology provides interactivity, non-linear communication, and a new economy in the mediums it brings forth. It causes an evolution of traditional media as characteristics of the technology are incorporated that change use and format in response to the new mediums. As digital technology influences mass media, it also carries cultural implications. New media technology is digital 
technology applied to mass communications. Obviously, the Internet is new media technology. So are satellite and cable data transmission, computer assisted research, multimedia publishing, and even word processing. The technology changes the way all media are produced, distributed, displayed, and stored. Digital media, when used correctly, has the ability to engage with consumers far more effectively than traditional media. This is due to several factors including the interactive nature of digital, the targeted nature of digital, the social nature of digital and the medium's inherent ability to measure engagement and not just reach. When someone drives past your billboard, it is impossible to tell whether or not they took any notice.

New media also represent a shift in the manner in which you go about digesting your daily allotment of media, and they define new roles that you play as a consumer and as a producer. (Before we delve any deeper, it's important to point out that even though technological advances have provided many new options, old media are still around and are still of vital importance. They haven't disappeared and likely will not for decades, perhaps not ever.)

Newspapers are transforming to adapt to the changing media landscape and are now providing a compelling, integrated experience for readers and advertisers alike. Depending on whom you ask about the future of media and journalism, it's either the best of times or the worst of times. The impacts of the changing media landscape on news are pulling in two opposite directions and analysis often weighs to one extreme or the other. One extreme is that online and other new forms of more decentralised news will finally liberate readers from partisan news monopolies which have tended to become more and more concentrated and to dominate the production and access to news. The other extreme is that the demise of the traditional news media is before us (partially caused by the rise of the Internet) and with it an important foundation for democratic societies is at risk.In the not too distant past, most media-both print and electronic forms-were delivered to you primarily in a definitively chronological format. You read newspapers, magazines, and books. You watched television, listened to the radio, and went to the movies. Most media of this type were designed-and often still are-to be consumed in a linear fashion, from beginning to end. Though it's not that hard to break the inherent structure of most linear media by simple actions such as flipping through a magazine from back to front or starting a DVD up in the middle of the film, the obvious fact is that the creators of this type of content intend to present information within a logical chronological structure. Yes, you clearly have the ability to break the chronological order of most old media content, but that's not what producers intend for you to do.

Today, though you still receive a significant portion of information from old media channels, it's also possible to keep up with the news, view educational programs, watch sit-coms, and listen to music by tapping into new platforms and delivery mechanisms that, in addition to providing a wide array of raw information, provide you with opportunities to interact directly with provided content. New media afford you the opportunity to engage with content in novel ways, ones you simply didn't have access to in the past. You can read a blog and leave comments in response to the writing, comments that are instantly accessible to all readers; you can play video games, either against another individual or against the computer itself; you can research virtually any topic using a Wiki and can contribute information to this type of Webbased resource about subjects in which you are knowledgeable; you can download podcasts to mobile devices and listen to them wherever and whenever you choose.
Given these examples and many others like them, it's not hard to see that recent technological advancements have changed the media world. These changes give you-consumer, user, or producer- many new possibilities to explore. The fact of the matter is that you now live in a world where direct interaction with the media that you encounter is not only possible but is increasingly the norm. Intelligent, sophisticated and-perhaps surprisingly-often easy-to-use technology is part of your daily life. No matter where people are or what they are doing, the vast majority carry devices that are continuously connected. Take for example the simple cell phone. These mobile devices have evolved from existing simply as phones into miniature, portable computers (think iPhone!). And speaking of computers, whether at home or the office, you're more likely to use portable laptops instead of plunking down in front of one of their bulkier cousins, those desktop real estate-hogging workstations, commonly used by most of us not so long ago. It's not just size and portability that differentiate the majority of computers in use today from their recent ancestors. Most computers that are used today are linked together- as well as to servers, printers, and other digital devices-via wireless networks rather than wired connections. And it's not just that mobile devices and wireless connections keep you hyper-connected, you're also likely to be connecting with, working via, and collaborating through virtual devices that you have no physical relationship with at all. You're just as likely today to backup your important digital data online as you are to a dedicated device that is physically attached to your computer. You're able to collaboratively create detailed text documents, spreadsheets, or visual presentations using "cloud" apps that run in a browser window rather than through software applications that are installed on the hard disk of your computer.

As noted earlier, the times they are a changing'! We've actually made great leaps from the earlier days of the digital media revolution where issues of convergence were of principal concern. That was the early era of the digital revolution when the shift from old media to new media was more painfully apparent. During those days, media producers were largely concerned with thinking about ways that new technology would allow them to distribute content of multiple types via multiple channels at the same time. The Web afforded content producers the ability to offer a wide variety of media forms-print, photography, video, animation, graphics, etc.-in one package and deliver it to the intended audience on a variety of platforms, the World Wide Web at the time was the most obvious. The changing media landscape is altering the power structure of the whole society, leading us to the better future.

That's pretty much what happened. As the Internet rose to become a dominant player within the plethora of media options available, producers found ways to leverage the technology toward delivering more content. A headline story appearing in the Sunday edition of the New York Times might be relegated to two, maybe three photos at most, but the Web-based version of the same story might contain fifteen to twenty. Information graphics were no longer fixed in static formats but could be animated or presented in the form of a step-bystep slide show of the relevant data. Today, we've moved past the point where convergence is the dominant concern. Convergence is more or less assumed at this point; it's simply part of the medium. Consumers now find themselves immersed in a more mature and sophisticated media landscape.

If you are a Digital Collaborator, you use information technology to work with and share your creations with others. You are enthusiastic 
about how ICTs help you connect with others and confident in your ability to manage digital devices and information. For you, the digital commons can be a camp, a lab, or a theater group - places to gather with others to develop something new. Relevant technologies, and their uses, have matured. Of course, digital is still the name of the game, but the possibilities have multiplied; the potential for interactivity is greater than ever before. Users have become the great contributors of much of the Web's content in stark contrast to the role of simple consumer that most were relegated to not long ago. The popular YouTube Web portal alone illustrates this point. Social media platforms and blogs provide audiences with the means to stay connected and to contribute content. Data-driven content management systems, the backbone on which many of the most information-rich Web sites are now built, allow content authors a way to distribute information without needing to understand the technical intricacies of Web development.

"Web 2.0," a term that generally refers to Web-based applications and platforms, makes it easy for users to collaborate, share, contribute, and author their own content, and is responsible for decentralizing the locus of content available to consumers like you. Whether you realize it or not, you've picked a thrilling time to learn about digital content production. Technology is evolving at a break-neck pace which, more often than not, is creating a great amount of potential for you as a content producer. You now have the opportunity to produce content for your client or employer-or for yourself for that matterand disseminate that information to a very broad audience. You have much greater control over the entire process. You might choose to be a writer, a photographer, a designer, or a filmmaker; in all actuality, the professional world that you're about to enter will probably ask you to be all of these and more. You're also preparing to enter the digital media profession at a daunting time, one full of new technologies and the complexities they entail. The career you pursue will be both exciting and complex. Technologies will in many ways define the choices that you make and the directions you take. Though it will be challenging, it's an exciting time to begin a career in visual communication, one rife with opportunities for you to exploit.

To my friends in old media, I'd say: If you haven't already, admit that the new-media thinkers were right -- because they were. The Internet would change everything, it would revolutionize and devastate the business you came to love, and there are people who saw this much earlier than you did. To my friends in the new media, I'd say: Kudos. You deserve acknowledgment for your vision and smart thinking. But now: Lower the barriers to entry in what used to be your world and yours alone. Newcomers are blessings to embrace, not Johnny-ComeLatelys to be mocked.

We journalists are back together again, or sure as heck should be, and the enemy now isn't the other side but the challenge of finding new ways and new models that will sustain the information needs of democracy. This work needs everyone's good thinking, and will be accomplished much more easily if it's not weighed down by old grudges and tribal loyalties. What a richer world this will be when newmedia thinkers critique new media with the same vigor they bring to old media, when old-media veterans feel free to say that old ways don't work and may not have been the greatest anyway.

\section{Current Theories}

New media technology theory began around the same time as the introduction of the computer. The trend of these theories is to examine the interplay of traditional and new media and to discuss the cultural impact of new media. The interplay and associated new developments is referred to as media convergence. Marshall McLuhan, an early theorist, said new forms of media result from the integration of multiple media [1]. Similarly, Fidler [2] said that traditional forms of media change in response to emerging new media. New media improve upon or remedy prior technologies [3]. Existing media are mixed and repurposed into new forms; media converge. Moreover, media development today is the convergence of different media industries and digital technology to produce multimedia [2].

Additionally, new media technology has changed the flow of communication from a linear to a three dimensional form of information. The roots of this philosophy lie in hypertext, which is a method of organizing and presenting information on a computer in an order at least partially determined by electronic links (hyperlinks) the user chooses to follow [3]. Thus, mass media grows from one way communication to incorporate interactive communication. Interactivity allows feedback to enter the system as every stage of the communication process, from acquiring and processing to storing and distributing. "As our ways of storing manipulating, and retrieving information change, so too do our perceptions of the world [4]." Much of our perception of the world is determined by our access to information.

New media technology introduced two major differences in media access. Time and geographic distance are insignificant with satellite and computer networks. The same hardware offers limitless channels of distribution that come without centralized control. These technological changes initiate new culture. McLuhan described this as the "global village" in which electronic communication would break down the barriers and obstacles encountered in traditional media by allowing people to see, experience, and understand more [2]. Similar to McLuhan, Bolter and Grusin explain that we define ourselves through our media. In traditional media, the audience understands the content from the producer's point of view. Interactivity allows the user to have controls over how and what content is viewed. Note how even the role of the audience has changed as reflected by the term "user." This operational freedom is significant to our culture because it corresponds, "to various attitudes about the role and value of the individual [3]." While media do not determine cultural or individual identity, the technology influences how we see ourselves and the world we live in.

\section{The Future of New Media}

Pretty amazing stuff, don't you think? As you dig a bit deeper into the topics - ones that will prepare you to become a producer of sophisticated digital media-you need to accomplish two objectives: 1) You need to understand the place in which you find yourself presently situated within the overall media landscape, and 2) You need to realize what it is that you're either actively doing or that you have the potential to be doing with all of this digital media. The coming decade's wave will provide all that information to people not just through desktop and laptop computers but via all mobile devices, vehicles, the electronic equivalents of flexible paper, and even television sets. Almost all the new mobile phone handsets are being designed as 'all-screen' models with full Internet access. Many top-of-the-line handsets are also being designed to receive streaming video signals (even if only through arrangement between the cellular carrier and television networks). Because most people replace their mobile phone handsets every two or three years, these new handsets mean that probably by the middle of this coming decade the number of people who have Internet access will 
increase from 1.8 billion to approximately 4.1 billion; the number who use mobile phones -60 percent of the world's population. Moreover, many of the world's major manufacturers of television sets, companies such as Sony, Samsung, and LG, have announced that most of their products in 2011 will be able to connect directly to the Internet. People will be able to view YouTube, Hulu, any other video streaming sites, as well as all Web sites, via their television sets. Television sets with Internet access will also be able to circumvent the limited number of television networks and channels available terrestrially or from local cable television service providers. Software programs (such as Livestation.com, a harbinger of what's to come) already allows users of personal computer, iPhone, or Android mobile phone handset to access more than 4,000 live television stations' broadcasts, and television sets connected to the Internet will have a similar capability. People with Internet-connected television will be able to access any of the thousands of television stations in the world that happens to stream their broadcasts online. Many television networks have already begun streaming high definition broadcasts into the Internet in anticipation of this trend. The result of this coming decade's wave will be that all information in text, audio, and video formats will be instantly available to the majority of the world's population wherever they are.

Thus during the past 30 to 40 years the cumulative effect of these waves of technological change is that for the majority of humanity access to news and information is changing from scarcity to surfeit. For examples, a Xhosa tribesman in South Africa with a Vodacom HTC Magic mobile handset has instant access to more information than the President of the United States did at the time of the tribesman's birth. So does a Bolivian girl to whose school was donated refurbished Macintosh computers. So does a Mongolian plumber who bought a Lenovo netbook for his son's education. Today, between 1.7 billion and 4.1 billion people can instantly obtain more information than could be contained in the ancient library of Alexandria, the Renaissance Era library of the Vatican, and the modern Library of Congress combined.

People aren't switching their media consumption from analog to digital for the sake of digital. Indeed, most find reading a newspaper, a magazine, or a book to be easier on paper than via a computer screen; or watching a television program on a television set or a movie on a theatrical screen to be a better experience than doing so on the smaller surface on a computer screen. The actual reason why people are switching their consumption is because digital gives them extraordinarily more choices and access to news, entertainment, and information. This is not only the greatest development in media since Gutenberg's press; it is the greatest media development in history.

\section{References}

1. McLuhan M, McLuhan E (1995) Zingrone F (Edn) Essential McLuhan. Basic Books, New York.

2. Fidler RF (1997) Mediamorphosis: Understanding new media. Pine Forge Press, Thousand Oaks, CA.

3. Bolter JD, GrusiR (1999) Remediation. Graphic Composition, Inc., United States.

4. Purves AC (1998) The Web of text and the Web of god. Guilford Press, New York.

5. Anderson C (2006) The Long Tail: How Endless Choice Is Creating Unlimited Demand. Random House Business Books.

6. Brown JS, Duguid P (2000) The Social Life of Information. President and fellows of Harvard College

7. Darley A (2000) Visual Digital Culture (Studies in Culture and Communication).
Routledge, an imprint of Taylor \& Francis Books Ltd.

8. Gladwell M (2006) Blink: The Power of Thinking without Thinking. Penguin books Ltd.

9. Clifton R, Maughan E (2000) Twenty Five Visions: The Future of Brands Macmillan Press Ltd.

10. Johnson S (2006) Everything Bad is Good for You: How Popular Culture Is Making Us Smarter. Penguin Books Ltd.

11. Kress K (2006) Reading Images: The Grammar of Visual Design. Routledge, an imprint of Taylor \& Francis Books Ltd.

12. Krug S (2000) Don't make me Think.

13. Que MN (1999) An Introduction to Visual Culture. Routledge, an imprint of Taylor \& Francis Books Ltd.

14. Tufte E (1990) Envisioning Information. Graphics Press, USA.

15. Weissman J (2003) Presenting to Win: The Art of Telling your Story. Financial Times Prentice Hall Getting Connected, Qualitative Conference Paper.

16. Wright J (2006) Blog Marketing. McGraw Hill Higher Education.

17. http://www.david-campbell.org/2011/05/23/the-new-media-landscape-1contours-of-change/

18. http://www.digitaldeliverance.com/2010/06/08/the-greatest-change-in-thehistory-of-media/

19. Beam C (1997) The character of content online: you need to understand why you're going online and then make it a real business. Folio: the Magazine of Magazine Management.

20. Isaacs SD (1994) The golden age maybe? (New media technology). Columbia Journalism Review 33.

21. Pavlik JC (1998) New media technology: Cultural and commercial perspectives. ( $2^{\text {nd }}$ edn), Needham Heights, MA, Allyn \& Bacon.

22. Singer JB, Craig D, Allen CW, Whitehouse V, Dimitrova A, et al. (1996) Attitudes of professors and students about new media technology. Journalism and Mass Communications Educator 51: 36-45. 